\title{
Fire Extinguishing System and Temperature Profile in Confined Space
}

\author{
In Ju Hwang, ${ }^{1}$ Choon-Hyoung Kang, ${ }^{2}$ Yangkyun Kim, ${ }^{1}$ and Seon Gyun Rho ${ }^{3 *}$ \\ ${ }^{1}$ Korea Institute of Civil Engineering and Building Technology, Goyang-si, Gyeonggi-do 10223, Korea \\ ${ }^{2}$ School of Chem. Eng., Chonnam National University, Gwangju 61186, Korea \\ ${ }^{3}$ Department of Fire Service Administration, Honam University, Gwangju 62399, Korea
}

(Received March 5, 2020; accepted April 22, 2020)

Keywords: fire extinguishing, cable fire, fire detection, temperature profile, confined space

In modern times, it is very important to ensure safety in the prevention, design, and maintenance of important facilities for fire protection. Fires occurring in important facilities such as industrial plants must be detected quickly, and the fire must be suppressed to minimize damage. For this purpose, it is necessary to accurately detect the fire and sound the fire alarm. To do this, it is very important to minimize the false alarm and improve the sensitivity of the fire detector. If devices are densely placed in a confined room, cables or switches with electrical contact are particularly vulnerable to fire. In this study, we evaluated a fire alarm and extinguishing system by considering the temperature profile during a cable fire in such a confined space. The fire detection algorithm and integrated management system developed in this study can be applied stably to the flame spreading fire because it can detect the fire faster than conventional detection systems. As compared with conventional smoke detectors, the delay time could be reduced by $20-30 \%$ for a fast-growing fire and by $30-60 \%$ for a smoldering fire.

\section{Introduction}

In recent years, as high-rise buildings and large-scale infrastructure construction projects have been constructed, fire and safety risks have increased significantly. In particular, as the infrastructure facilities related to electricity, communication, gas, heating, and water supply are concentrated in urban areas, for which systematic development plans have been established, it is warned that a fire would cause an unexpected amount of damage.

Fire prevention designs are important, and if a fire breaks out, it must be rapidly detected and suppressed to minimize damage. To do this, it is necessary to minimize the false alarm and improve the sensitivity of detectors for an accurate and rapid alarm in case of fire. To ensure a rapid fire detection, numerous recent studies have been carried out to improve the performance of detectors and develop/apply detectors suitable for diverse locations, including buildings, tunnels, and underground facilities. ${ }^{(1-5)}$

*Corresponding author: e-mail: skno@honam.ac.kr https://doi.org/10.18494/SAM.2020.2852 
Niua and Lia evaluated the gas diffusion and cross-sectional temperature changes in cable tunnels through numerical simulations of cable tunnel fires. ${ }^{(6)}$ It was reported that these processes and results can be used as criteria for establishing fire protection measures and selecting fire protection systems for cable tunnels.

Zhang and Zhao studied the smoke characteristics of utility tunnel fire cable compartments by experimental and numerical simulation methods. ${ }^{(7)}$ They showed that utility tunnel fires have distinct differences in maximum ceiling temperature and smoke distribution compared with road tunnel fires. It was proposed to close the fire door and run the mechanical ventilation mode after a fire occurs. Rose-Pehrsson et al. experimented with an early warning fire detection system using four sensor arrays and a probabilistic neural network. ${ }^{(8)}$ As a result, the composite sensor showed a higher performance than a smoke detector. ${ }^{(9)}$ Okoro and Idama improved the automatic fire management system by integrating signal detection filters and adopting energy emission prediction techniques to reduce the false alarm and failure rates. ${ }^{(10)}$

Gillespie et al. studied the performance-oriented fire safety code setup by analyzing fire safety parameters for cable fires in tunnels. ${ }^{(2)}$ Hsia and Guo studied the security system of multiagent architecture with a multisensor structure and a multicommunication interface. ${ }^{(11)}$ They tried to improve the accuracy of judgment on events by using fuzzy-AHP algorithms to warn of disasters early. Takei et al. introduced an odor detection system for an early fire detection to detect fire early. ${ }^{(12)}$ Kim et al. experimented with an early warning fire detection system using four sensor arrays and a probabilistic neural network. ${ }^{(13)}$ As a result, the composite sensor showed a higher performance than the smoke detector. Other studies have examined methods of minimizing error rates by applying appropriate detectors to facilities and approaches for adjusting the sensitivity of detectors for prompt alarms. ${ }^{(14)}$ In addition, algorithms that apply a multisensor system to improve the performance of an automatic fire detection system and use combinations of detection signals have been introduced. ${ }^{(15)}$ However, the problem of false or missing alarms has not been properly solved using the proposed algorithms.

For this reason, in this study, we investigated the improvement in the reliability of fire detection and the reduction in response delay at the monitoring location of an underground cavity utility tunnel. As the first step, different fire detection sensors were applied to the target space. Then, we used the inference method based on rules and cases to calculate and compare the changes in detection signals. A rule-based inference algorithm makes comparative judgments about detection signals using physical quantities and the changes in these quantities over time as references. A case-based inference algorithm analyzes the correlation between datasets by comparing the change in a detection signal with data that are quantified on the basis of past fire cases and the response characteristics of a detector. The combination of these methods minimizes the response delay of the detector and improves the reliability of the detection signal.

\section{Procedure}

\subsection{Experimental setup}

Figure 1 shows the overall diagram for evaluating a prototype fire extinguishing system. The space for installing an underground lifeline was reproduced in a model by considering 


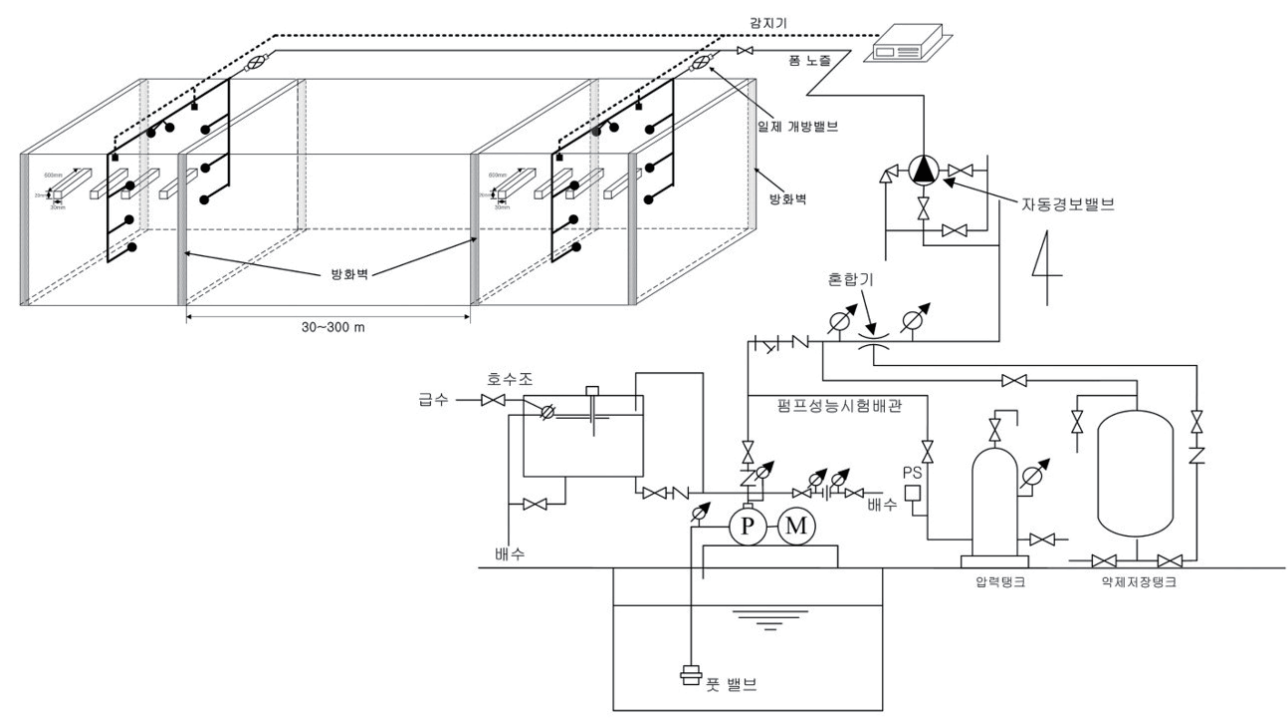

Fig. 1. Overall schematic diagram of the fire extinguishing system.

the scale of the experiment. The length of the model was $6 \mathrm{~m}$, and its cross-sectional area was $2 \times 2 \mathrm{~m}^{2}$. These dimensions were similar to those of an actual underground cavity utility tunnel. To simulate the confined zone designed by this study, a fire door and a fire wall were installed at a distance of $2 \mathrm{~m}$ in the longitudinal direction. Figure 2 shows the location of the temperature sensor in the fire extinguishing system in Fig. 1. As shown in Fig. 3, cable trays were installed on the left-side and right-side walls in the zone, and insulated cables were installed in the trays. The extinguishing agent discharge system and a piping system were fabricated as illustrated in Fig. 1. In this study, we used a foam head that we developed and designed ourselves, and the pressure equipment used a high-performance fire pump. The foam head was installed at the ceiling center of the fire zone at an angle of $30^{\circ}$ in the cable direction. In addition, three foam heads were installed on the right-side wall and connected to a single service pipe. This arrangement was used to evaluate the discharge rate of the foam. The foam heads were connected to a foam extinguishing nozzle, and they absorbed an agent using the negative pressure generated by the water passing through the nozzle neck. Air, water, and the agent were mixed at the nozzle outlet.

Visualization windows fabricated from tempered glass were installed at both sides of the experimental setup to visualize the foam heads and the ignition of the cable. Three-lay $22.9 \mathrm{kV}$ cables were arranged in four rows on the wall opposite to the foam head as shown in Fig. 3.

A composite detector and a temperature sensor were installed on the ceiling to identify the temperature and smoke generation characteristics in the space when a fire breaks out. In addition, temperature sensors were installed vertically from the bottom, which included the surface of the cable sheath, for real-time temperature measurement.

\subsection{Method}

To simulate a cable fire, a stainless pipe with high resistance was inserted into the $22.9 \mathrm{kV}$ cables, and the space between the cables and the pipe was sealed using plaster cloth at both 


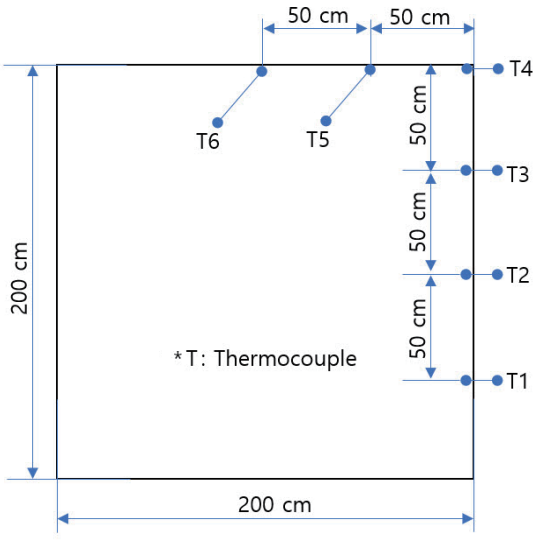

(a) Cross section

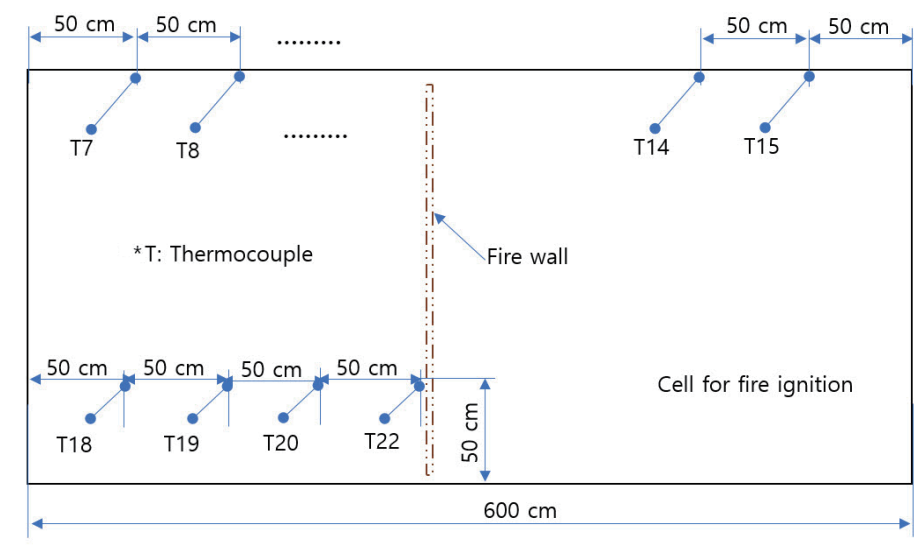

(b) Longitudinal section

Fig. 2. (Color online) Schematic diagram of the positions of the temperature sensors in the fire extinguishing system.
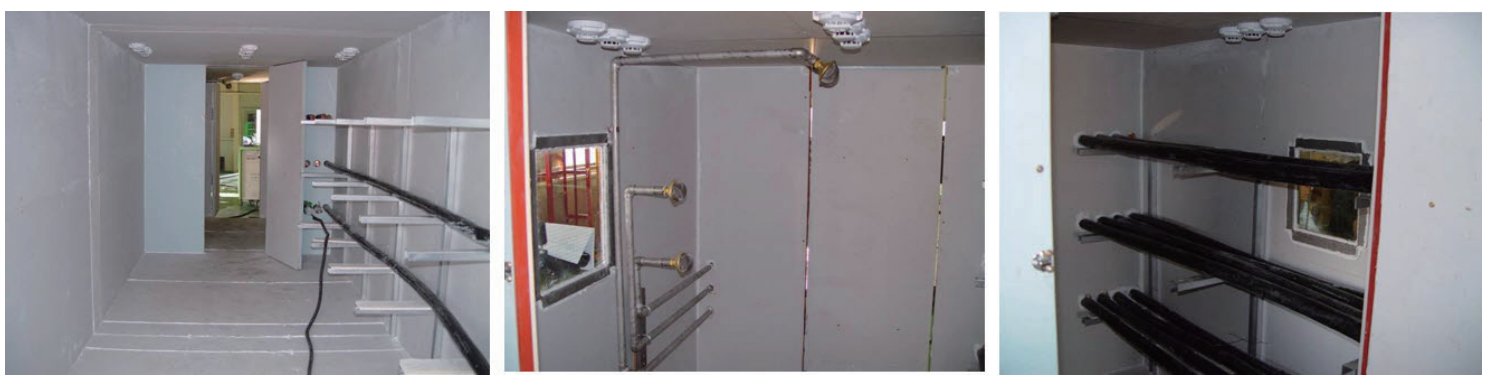

Fig. 3. (Color online) Form head and cable layout inside the prototype experimental equipment.

ends. Then, the left and right sides of the pipe were connected to power supply terminals that provided a maximum current of $1200 \mathrm{~A}$. Figure 4 shows a cable connected to an overcurrent generator for the basic experiment. The cable was sufficiently long to be connected to the overcurrent generator at a point well outside the prototype experimental system. Fire walls were installed in front of and behind the prototype experimental system. In addition, a door was installed to make the system accessible.

Twenty-two k-type thermocouples were installed to measure temperatures of the ceiling, walls, and cables of the experimental system. The change in temperature over time was recorded using a data acquisition device as shown in Fig. 5. The main experimental process was as follows: After the overcurrent generator was switched on, the stainless steel pipe inside the $22.9 \mathrm{kV}$ cables was overheated by increasing current. The temperature data acquisition device and detection system started operating immediately before current was applied. Each thermocouple recorded temperatures over time, and the detection system recorded digital and analog signals when it sensed heat and smoke. The ion-type smoke detector sent a signal when smoke occurred. If a set temperature was exceeded, a fire signal was sent to the driver of the fire extinguishing system. When the automatic fire extinguishing system received a signal, it automatically opened the pipe and discharged foam in the fire control area of the prototype 

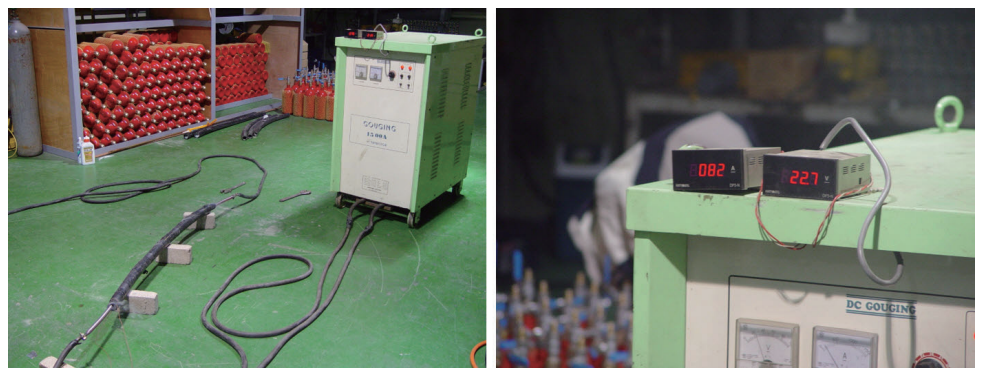

Fig. 4. (Color online) Cable shape diagram connected to the overcurrent generator.
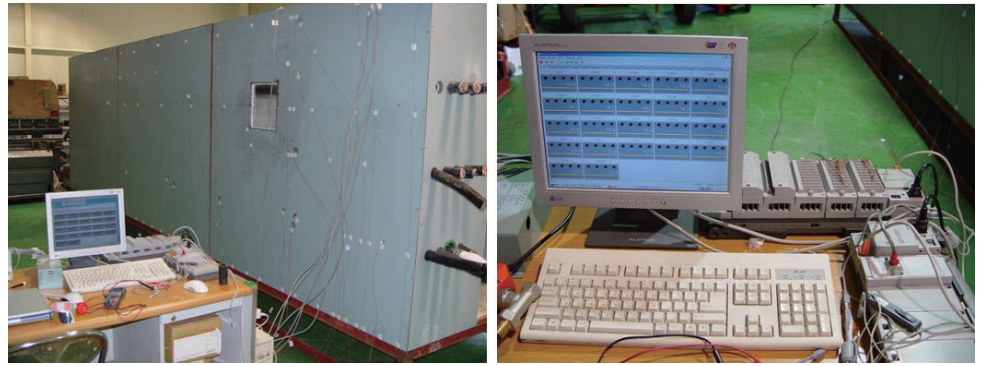

Fig. 5. (Color online) Thermocouple and data acquisition system for temperature measurement in prototype equipment.

experimental system. The signals obtained from the smoke and heat detectors installed on the ceiling were analyzed to issue fire caution and warning. The corresponding control signals were used to operate the valve driver and discharge foam.

\section{Results and Discussion}

\subsection{Cable fire}

Before the prototype evaluation experiment, a basic experiment was performed to observe whether the cables were excessively heated. When a current of $145 \mathrm{~A}$ was applied at $9.3 \mathrm{~V}$ to the cables in which the stainless steel pipe was inserted, smoke occurred after approximately $180 \mathrm{~s}$ and the cables ignited after approximately $240 \mathrm{~s}$.

The insulating material that covered the cable core ignited above a certain temperature and continued to burn. The fire developed in the longitudinal direction of the cable as the cable sheath, which is the exterior part, ignited as shown in Fig. 6.

\subsection{Integrated body}

The same process as that of the basic experiment was applied after specimens, which had been fabricated in advance, were installed. Two types of fire, i.e., fast-growing fire and smoldering fire, were distinguished in the experiment. 


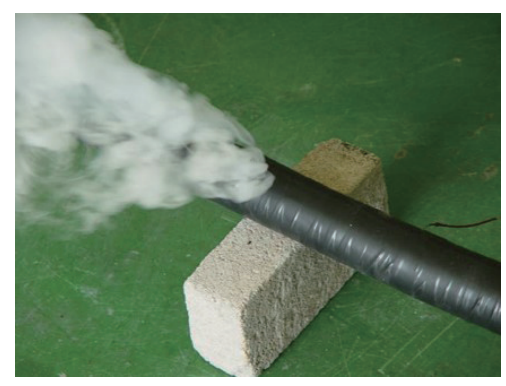

(a)

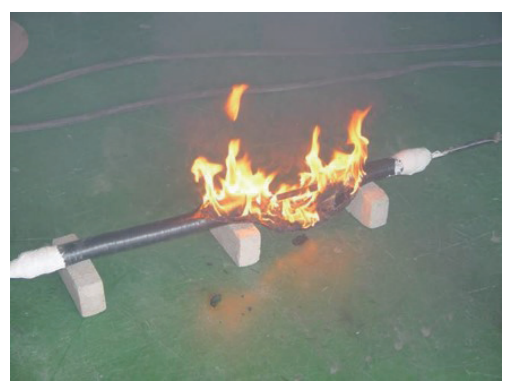

(c)

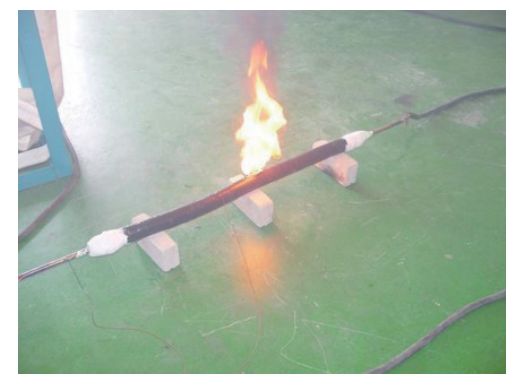

(b)

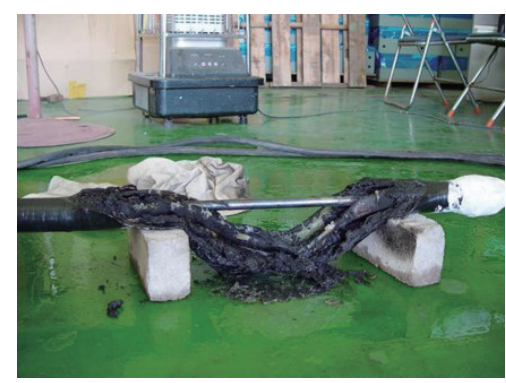

(d)

Fig. 6. (Color online) Ignition of cable owing to overcurrent and suppression of fire. (a) Smoke. (b) Flame. (c) Flame development. (d) After burning.

In the case of a fast-growing fire, the detector sensed smoke approximately 3 min after a load was applied and transmitted a caution signal. Flames occurred after approximately 5 min, when the heat detector started sending a signal (see Fig. 7). Figures 8 and 9 show the temperature distribution at the location of each thermocouple in our fire extinguishing system experiment.

As shown in Fig. 2, thermocouples 1-4 were installed vertically on the wall at a spacing of $50 \mathrm{~cm}$. Thermocouples 5 and 6 were placed transversely towards the center of the ceiling at a spacing of $50 \mathrm{~cm}$. Thermocouples $7-15$ were installed in the longitudinal direction of the ceiling at a spacing of $50 \mathrm{~cm}$.

In addition, thermocouples 16,17 , and 21 were installed to measure temperatures at the cable surface, inside the cable, and at the cable core (stainless pipe). Thermocouples 18-20 and 22 were transversely installed at a height of $50 \mathrm{~cm}$ from the bottom outside the fire control area.

The temperature of the cable core (TC 21) reached almost $550{ }^{\circ} \mathrm{C}$ in $100 \mathrm{~s}$. However, the temperature between the sheath (insulating material) that covered the core and the cable surface (TC 17) reached approximately $100{ }^{\circ} \mathrm{C}$ in $180 \mathrm{~s}$. The temperature of the cable surface began to increase in $120 \mathrm{~s}$.

This indicates that the cable sheath (insulating material) and surface were effective in heat insulation. However, when the temperature of the cable core continued to be higher than a certain level, the insulating material ignited and continued to burn. 

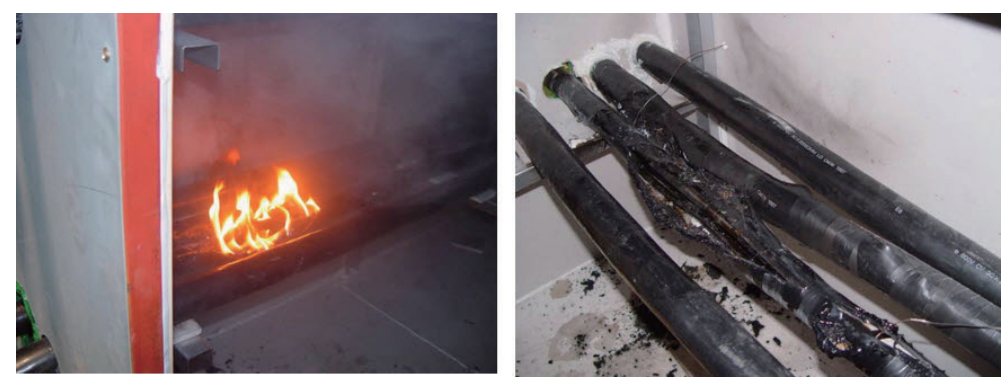

Fig. 7. (Color online) Cable ignition inside the prototype owing to overcurrent (1st experiment).

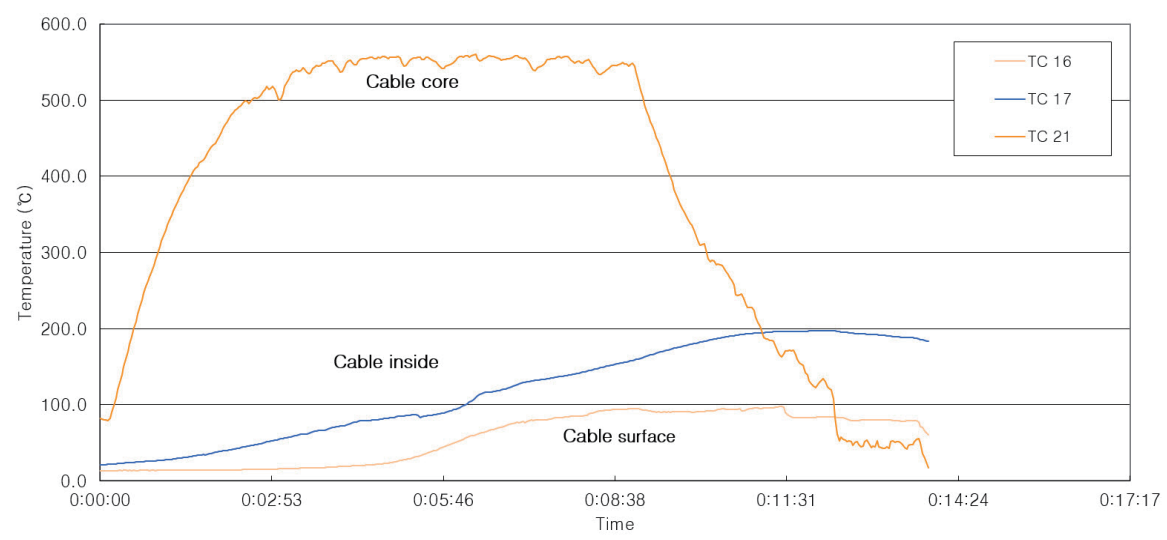

Fig. 8. (Color online) Temperature distributions of the cable and interior of the prototype experimental system during cable fire.

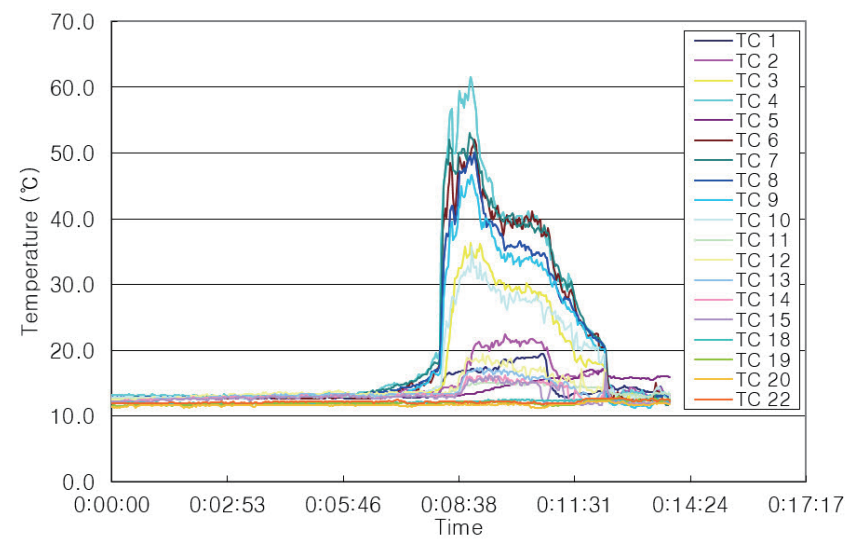

Fig. 9. (Color online) Temperature distributions inside the prototype experimental system during cable fire.

As shown in Figs. 8 and 9, the temperature distribution in the fire control area of the prototype experimental system demonstrated that thermocouple 4, which was located on the ceiling above the cable, reached the highest temperature in $200 \mathrm{~s}$.

The second highest temperature was shown by thermocouple 7, which was located at the first edge in the longitudinal direction on the ceiling. This was followed by thermocouple 6 , which 

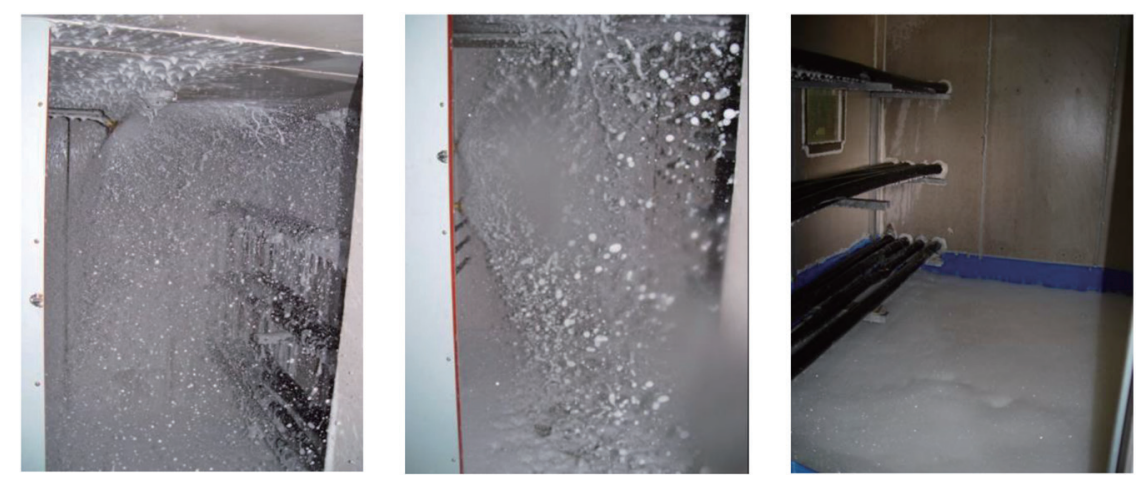

Fig. 10. (Color online) Foam discharge inside the experimental space (without ignition, 2nd experiment).

was located at the center of the ceiling, thermocouple 8 , which was between thermocouples 6 and 7 , and thermocouple 9 , which was at a distance of $50 \mathrm{~cm}$ from thermocouple 8 in the longitudinal direction.

Moreover, high-temperature distributions were exhibited by thermocouple 3, which was located at the third point on the wall where the cable was installed, and thermocouple 10, which was located at a distance of $50 \mathrm{~cm}$ from thermocouple 9 in the longitudinal direction of the ceiling. Accordingly, high-temperature distributions were observed in the fire control area at the edge and at the longitudinal center of the ceiling, where a fire broke out.

The second experiment was performed under the same conditions. In the case of a fastgrowing fire, the integrated management system transmitted an alarm signal approximately 4 min after smoke was observed from the cable, and the foam extinguishing system automatically operated to suppress the fire.

Figure 10 shows the discharge operation of the foam heads and the confined space of the prototype experimental system, which was filled with discharged foam. It was clear that the foam heads installed on the ceiling in the cable direction could comprehensively suppress a fire from the bottom to the ceiling.

As soon as foam was discharged from the foam heads, the fire was completely suppressed. After $1 \mathrm{~min}$ of the discharge, approximately $1 / 4$ of the confined space of the prototype experimental system was filled with foam. This state continued for over $1 \mathrm{~h}$.

\section{Conclusion}

In the case of a smoldering fire, where fire development tends to be delayed, flames occurred approximately 20-25 min after load application by adjusting the overcurrent. At this time, smoke was detected approximately 8 min after the load was applied, and at the same time, similarity and weight increased significantly, and a fire alert was sent in approximately 9 min.

Accordingly, the fire detection algorithm and integrated management system developed in this study can be stably applied to such a smoldering fire because flames occur at a considerable time after smoke is sensed. 
In contrast, in the case of a fast-growing fire, the time interval between the alert and the alarm is short. For this reason, it is necessary to set the fire alarm signal to be released in the latter part of the alert stage.

(1) The smoke detection patterns in the prototype experimental system were comparatively analyzed. As compared with conventional smoke detectors, the detection time could be reduced by $20-30 \%$ for a fast-growing fire and $30-60 \%$ for a smoldering fire.

(2) As the confined space for fire control contained several planes where foam could be reflected or attached, the foam sprinkler heads effectively discharged foam to cable surfaces. Thus, the fire source was suppressed and fire development was effectively prevented.

\section{Acknowledgments}

This study was supported by a grant (19IFIP-B089072-06) from the Ministry of Land Transportation Technology Business Support Program funded by the Ministry of Land, Infrastructure and Transport of the Korean government.

\section{References}

1 E. Braun: NBSIR 81-2292 (1981). https://nvlpubs.nist.gov/nistpubs/Legacy/IR/nbsir81-2292.pdf

2 R. Gillespie, E. Soja, and J. Mawhinney: INTERFLAM 99 (Fire Science and Engineering Conference, 1999) 367-378. https://www.tib.eu/en/search/id/BLCP\%3ACN032611120/Setting-fire-safety-parameters-for-apower-cable/

3 O. Asif, Md. B. Hossain, M. Hasan, M. T. Rahman, and M. E. H. Chowdhury: Int. J. Commun. Network Syst. Sci. 7 (2014) 386. https://www.researchgate.net/publication/266079970_Fire-Detectors_Review_and_Design_ of_an_Automated_Quick_Responsive_Fire-Alarm_System_Based_on_SMS

4 W. Xihuai, X. Jianmei, and B. Minzhong: Proc. ICSP2000 (IEEE 2000) 1602-1605. https://ieeexplore.iee.org/ document $/ 893407$

5 M. S. Tomar: Suppression, Detection and Signaling Research and Applications Symp. (2016) 1-17. https:// www.nfpa.org/-/media/Files/News-and-Research/Resources/Research-Foundation/Symposia/2016SUPDET/2016-Papers/SUPDET2016Tomar.ashx?la=en

6 Y. Niua and W. Lia: Procedia Eng. 43 (2012) 569. https://doi.org/10.1016/j.proeng.2012.08.100

7 H. Zhang and Y. Zhao: Hindawi Adv. Civil Eng. 2020 (2020) 1 (Article ID 9128704). https://doi. org/10.1155/2020/9128704

8 S. L. Rose-Pehrsson, S. J. Hart, T. T. Street, F. W. Williams, M. H. Hammond, D. T. Gottuk, M. T. Wright, and J. T. Wong: Fire Technol. 39 (2003) 147. https://doi.org/10.1023/A:1024260130050

9 D. T. Gottuk, M. J. Peatross, R. J. Roby, and C. L. Beyler: Fire Safety J. 37 (2002) 381. https://tsapps.nist.gov/ publication/get_pdf.cfm?pub_id=916590

10 I. C. Okoro and O. Idama: Am. J. Eng. Res. 6 (2017) 19. https://www.semanticscholar.org/paper/A-Model-ofAutomatic-Fire-Detection-and-Suppression-Omokaro/8342aeafdf244ef2570d9d2c93bff0252941b2ea

11 K. H. Hsia and J. H. Guo: Sens. Mater. 29 (2017) 1069. https://myukk.org/SM2017/sm_pdf/SM1400.pdf

12 Y. Takei, T. Tashiro, T. Misawa, H. Nanto, H. Kasahara, and Y. Iwasaki: Sens. Mater. 17 (2005) 413. https:// myukk.org/SM2017/sm_pdf/SM619.pdf

13 H. S. Kim, I. J. Hwang, and Y. J. Kim: Proc. SAREK 2016 Summer Annu. Conf. (2016) 1379-1384. http:// www.koreascience.or.kr/article/CFKO200330839584193.pub

14 B. J. Kim and J. H. Kim: J. Korean Soc. Safety 29 (2014) 47. https://doi.org/10.14346/JKOSOS.2014.29.5.047

15 M. W. Hsu, S. K. Lee, L. L. Huang, Y. K. Chen, and C. M. Wu: Sens. Mater. 29 (2017) 429. https://myukk.org/ SM2017/sm_pdf/SM1336.pdf 


\section{About the Authors}

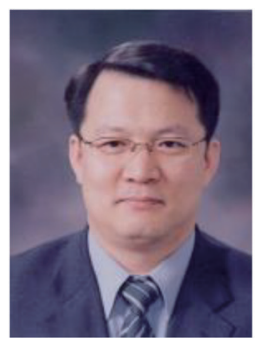

In Ju Hwang is a senior research fellow of Extreme Engineering Research Center, Korea Institute of Civil Engineering and Building Technology, Goyang-si, Korea. He received his Ph.D. in mechanical engineering from Sungkyunkwan University. His research interests include hybrid-renewable energy system, thermo-acoustic heat transfer, and supercritical phenomena. (ijhwang@kict.re.kr)

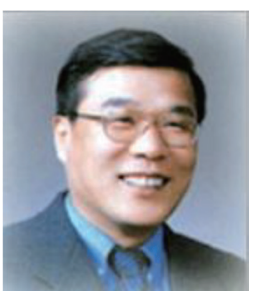

Choon-Hyoung Kang is a professor of the School of Chemical Engineering, Chonnam National University, Gwangju, Korea. He received his Ph.D in chemical engineering from the University of Delaware. His research interests include thermodynamics of polymer solutions, supercritical fluid technologies and process simulation and optimization. (chkang@jnu.ac.kr)

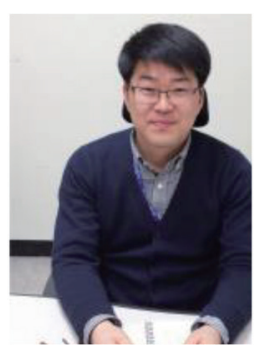

Yangkyun Kim is a senior researcher of Fire Safety Research Center, Korea Institute of Civil Engineering and Building Technology, Hwasung-si, Korea. He received his Ph.D. in mechanical engineering from Hokkaido University. His research interests include hydrogen safety, fire, and explosion physics. (yangkyunkim@kict.re.kr)

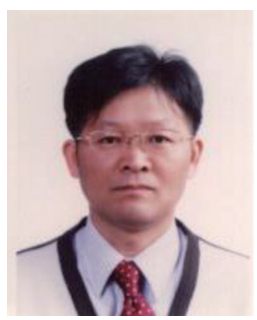

Seon Gyun Rho is a professor of the Department of Fire Service Administration, Honam University, Gwangju, Korea. He received his Ph.D in chemical engineering from Chonnam National University. His research interests include thermodynamics of polymer solutions, supercritical fluid technologies, and redox flow batteries. (skno@honam.ac.kr) 